\title{
Pulmonary Rehabilitation in Patients with Idiopathic Pulmonary Fibrosis - A Review
}

\author{
K. Kenn ${ }^{\mathrm{a}} \quad$ R. Gloeckl ${ }^{\mathrm{a}} \quad$ J. Behr ${ }^{\mathrm{b}}$ \\ ${ }^{a}$ Schoen Klinik Berchtesgadener Land, Department of Respiratory Medicine, Schoenau am Koenigssee, and \\ ${ }^{\mathrm{b}}$ Klinikum der Universität München - Campus Grosshadern, Medizinische Klinik und Poliklinik V, Comprehensive \\ Pneumology Center Munich (CPC-M), Munich, Germany
}

\section{Key Words}

Pulmonary rehabilitation - Idiopathic pulmonary fibrosis .

Exercise $\cdot$ Training $\cdot$ Review

\begin{abstract}
Among the various types of interstitial lung diseases, idiopathic pulmonary fibrosis (IPF) is the most common disorder and has a poor prognosis and a limited response to pharmacological treatment. In patients with IPF, functional exercise tolerance and quality of life have been shown to be significantly decreased. Current IPF guidelines suggest only a weak recommendation for pulmonary rehabilitation (PR). However, PR is regarded as a reasonable choice for the majority of patients with IPF. This review will summarize all of the available studies that have investigated the effects of PR in patients with IPF so far. Although only a small number of studies have been published to date, most studies have found significant short-term improvements in functional exercise capacity, quality of life, and level of perceived dyspnea. Long-term improvements or maintenance strategies of PR in IPF patients have not been adequately investigated yet. Up to now there is still no sufficient evidence for the recommendation of PR in IPF. However, physical training seems to be the major component of all PR programs. The current review will discuss potential exercise training regimens for patients with IPF and suggest additional useful modalities of a specific multidisciplinary PR program for IPF patients. Based on
\end{abstract}

the current literature and our own experience, this article will try to highlight the importance of PR as an additional, beneficial therapeutic option for patients with IPF.

(c) 2013 S. Karger AG, Basel

\section{Introduction}

Idiopathic pulmonary fibrosis (IPF) is a chronic fibrotic lung disease of unknown cause which is diagnosed predominantly in elderly males [1]. The relentlessly progressive course of the disease leads to premature disability and death, with a median survival of 2-4 years after diagnosis [1]. A definite diagnosis of IPF requires histologic or radiologic (high-resolution computed tomography) evidence of an usual interstitial pneumonia (UIP) pattern and the exclusion of known causes of pulmonary fibrosis [2]. Pirfenidone has been shown to reduce the decline of pulmonary function and exercise tolerance in mild to moderate

Previous articles in this series: 1. Cottin V, Camus P: Practical issues and challenges in idiopathic pulmonary fibrosis. Respiration 2013;86:1-4. 2. Poletti V, Ravaglia C, Buccioli M, Tantalocco P, Piciucchi S, Dubini A, Carloni A, Chilosi M, Tomassetti S: Idiopathic pulmonary fibrosis: diagnosis and prognostic evaluation. Respiration 2013;86:5-12.

K. Kenn and R. Gloeckl contributed equally to the preparation of this paper.

\section{KARGER}

E-Mail karger@karger.com

www.karger.com/res
(C) 2013 S. Karger AG, Basel

0025-7931/13/0862-0089\$38.00/0
Klaus Kenn

Schoen Klinik Berchtesgadener Land

Malterhoeh 1

DE-83471 Schoenau am Königssee (Germany)

E-Mail KKenn@Schoen-Kliniken.de 
IPF and is currently approved in the EU and Japan for the pharmacological treatment of IPF. Alternatively, n-acetylcysteine may also reduce the decline of lung function and is used off-label to treat IPF. Currently available pharmacological therapies are capable to slow disease progression and physical deterioration, but improvements are rarely observed and cure is illusive [1]. In addition, long-term oxygen therapy (LTOT) and supportive therapies for cough and comorbidities are offered to the patients [1]. In the face of a severe and fatal disease, lung transplantation is a viable treatment option for eligible patients who, however, are a minority within the IPF population, mainly due to progressed age and comorbidities [1]. Taken together, quality of life, exercise capacity, and life expectancy are severely impaired in IPF patients, and available treatments - except for lung transplantation - are palliative [3]. Therefore, pulmonary rehabilitation (PR) may be of added value for stable IPF patients in an attempt to improve their ability to cope with daily living.

\section{The Rationale for PR in IPF Patients}

IPF is a chronic progressive lung disease leading to increasing levels of dyspnea, dry cough symptoms, and fatigue, inducing reduced exercise capacity and health-related quality of life (HRQL) [4]. For patients with chronic obstructive pulmonary disease (COPD), there is a great deal of evidence that $P R$ programs have various significant and clinically meaningful benefits such as improved exercise capacity, HRQL, and symptoms of dyspnea. COPD patients are especially limited by impaired respiratory mechanics, hyperinflation, and musculoskeletal dysfunction. The benefits of PR in these clinical outcome parameters have been widely investigated and are well proven in patients with COPD [5-7]. In patients with IPF an impaired gas exchange seems to be the major cause of exercise intolerance $[1,8,9]$.

After dyspnea, the most important symptoms patients of both chronic lung diseases also suffer from are extrapulmonary manifestations like reduced exercise tolerance and HRQL, fatigue, and/or anxiety and depression [9-13].

Even if IPF and COPD are entities with very different pathophysiological mechanisms, in many respects they lead to some similar limitations for patients' everyday life and thus may reflect a similar burden of disease. With regard to these similarities, it seems plausible that PR may also be beneficial in patients with IPF.

$\mathrm{PR}$ as a comprehensive, multidisciplinary program uses a combination of exercise training, education, and behavior modification techniques to optimize functional capacity, improve self-management, reduce symptoms, and increase participation in activities of daily living (ADL) in patients with chronic lung disease [6]. As IPF is a disease with a limited response to conventional pharmacological treatment [14], PR as a nonpharmacological approach may be promising also in these patients. The American Thoracic Society (ATS)/European Respiratory Society (ERS) statement on PR from 2006 expressed that '... there are no formal evidence-based guidelines regarding the exercise prescription or response to exercise training for patients with respiratory disorders other than COPD. Therefore, recommendations for PR concerning these diseases can only rely on expert opinion based on knowledge of the underlying pathophysiological and clinical experience' [6]. The ATS/ERS statement is currently being updated and will be published in 2013. Most likely the level of evidence of PR in patients with IPF can be expected to be strengthened. However, an official statement [1] of the ATS, the ERS, the Japanese Respiratory Society (JRS), and the Latin American Thoracic Association (ALAT) concluded that '... the recommendation for PR in patients with IPF is weak. Nevertheless, it is stated that ... PR should be used in the majority of patients with IPF, but not using PR may also be a reasonable choice in a minority. Further research is very likely to have an important impact on the boards' confidence in the estimate of effect and is likely to change the estimate' [1].

Since IPF is known as a heterogeneous disorder in terms of disease progression, response to therapy, and prognosis [1], the optimal timing of PR in the disease trajectory is still unknown and requires further elaboration [15]. It is still unclear whether the decline in functional capacity could be decelerated or delayed if patients are referred to PR in any phase of the disease. So far there is no data showing the potential influence of PR on the clinical course or even on the prognosis of the disease. This review will highlight the current knowledge concerning the various components of a comprehensive PR process.

\section{Exercise Training Regimens in IPF}

The authors of the current review identified via a literature search 7 studies that investigated $P R$ in patients with IPF (table 1). PR duration varied from 6 to 12 weeks and was applied mostly as outpatient PR. In only a few studies was PR offered in a home-based fashion. Most studies included only a small sample size $(\mathrm{n}=17,17,21$, 


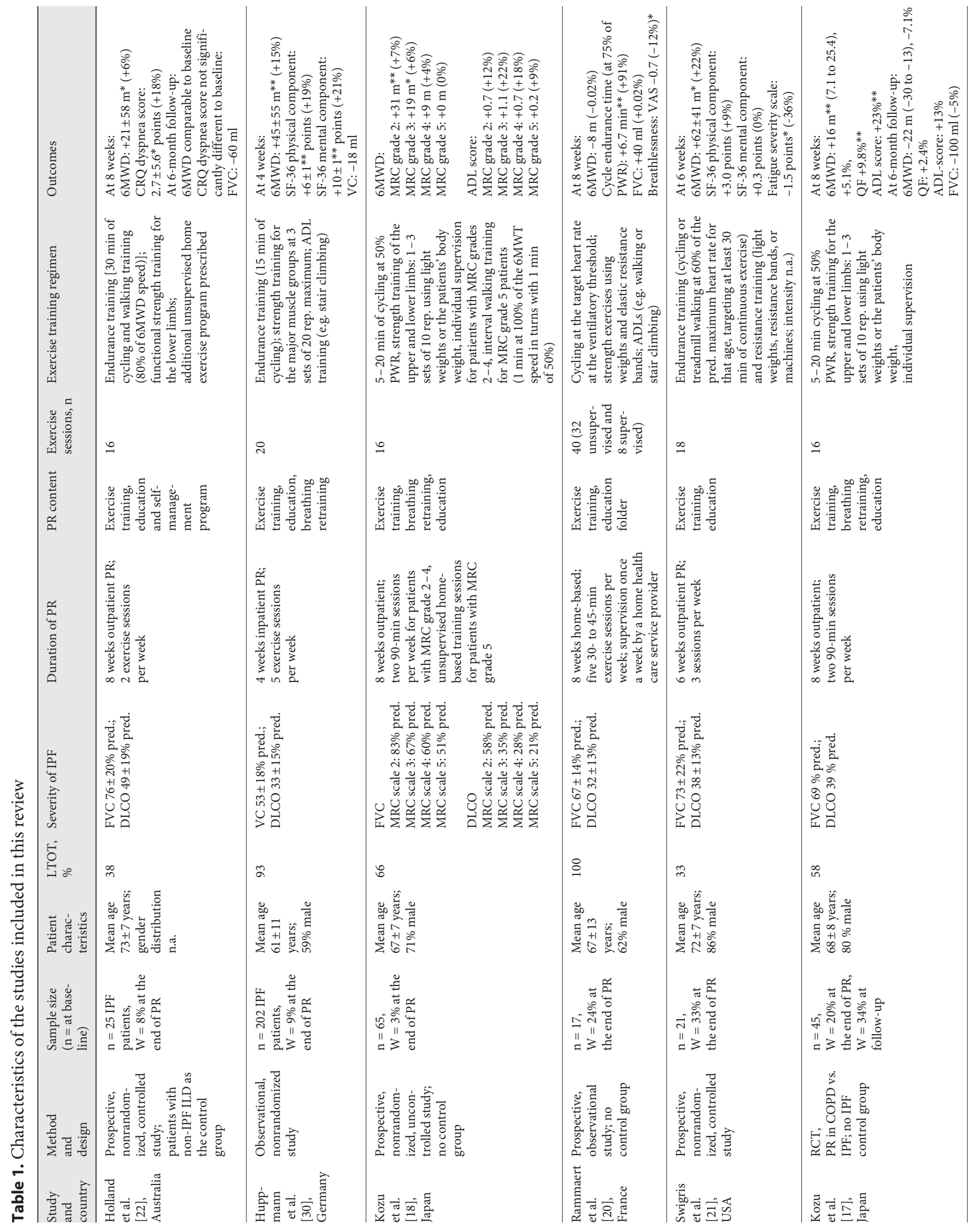




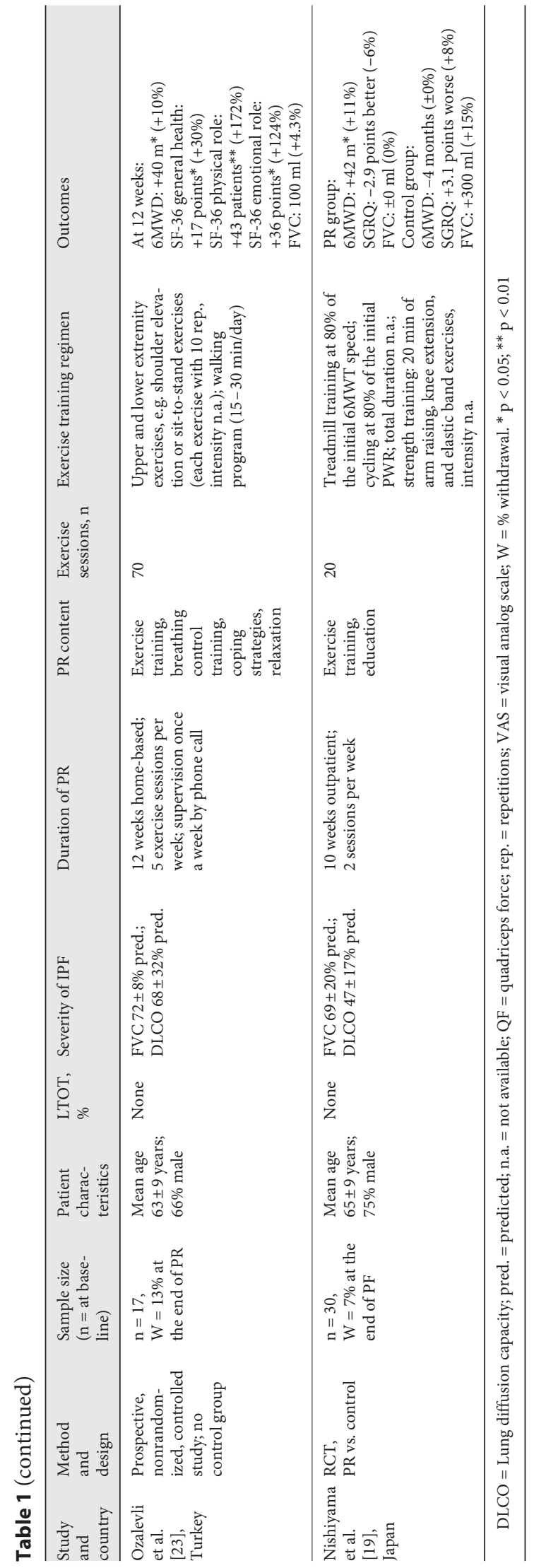

$25,30,34,45$, and 65$)$ and varied in scientific quality (from prospective, observational studies without a control group to randomized, controlled trials). In all of these studies exercise training was the major component. All trials provided a combination of endurance and strength training modalities as is also recommended in patients with COPD [16, 60]. Endurance training was performed on a stationary cycle ergometer or as a walking program on a treadmill or on the ground. If specified, cycling training was applied for sessions of 5-30 min. Training intensity was adjusted either to $50 \%[17,18]$ or to $80 \%$ [19] of the peak work rate (PWR), to the target heart rate at the ventilatory threshold [20], or to $60 \%$ of the predicted maximum heart rate for that age [21]. All cycle training protocols were based on continuous endurance training programs. None of the studies provided information on the feasibility of those endurance training protocols. When available, walking-based training programs were applied at $80 \%$ of the 6 -min walk test (6MWT) speed [19, 22 ] or at $60 \%$ of the predicted maximum heart rate for that age [21]. In the study of Kozu et al. [18], a ground walking-based endurance training program for severely disabled IPF patients $[\mathrm{n}=15$, forced vital capacity (FVC) $=51 \%$ predicted, MRC scale 5] was conducted using an interval training approach ( $1 \mathrm{~min}$ at $100 \%$ of the $6 \mathrm{MWT}$ speed in turns with $1 \mathrm{~min}$ of $50 \%$ ). No information was provided on the total exercise duration or on how the patients controlled their walking speed on the ground.

Strength training regimens within these studies included even more heterogeneous approaches. Most studies [19-22] did not provide detailed information on how resistance training was applied. It was only mentioned that 'functional strength training was performed'. Other studies $[17,18,23]$ described that $1-3$ sets of 10 repetitions of strength training for the upper and lower limbs were used. None of the studies provided any information about the level of intensity at which resistance training was performed.

The analyzed studies showed, in general, large variations in the described exercise modalities, duration, and intensity. Therefore, it is not possible to derive any consistent training protocol for an ideal exercise training program from the included studies. However, even different training regimens seem beneficial for patients with IPF, if applied.

No exercise-related adverse effects were mentioned in any study. This finding supports the conclusion of a Cochrane Review which stated that physical training is safe for subjects suffering from interstitial lung disease (ILD) [24]. 


\section{Education and Breathing Retraining}

An educational part was also a component of PR programs in several studies. In most educational programs information on breathing techniques, coping strategies, pacing during $\mathrm{ADL}$, and energy conservation were provided $[17-19,21]$. None of these trials offered detailed information on the specific content of these education sessions. Further studies should evaluate the particular needs of IPF patients and develop IPF-specific educational programs.

One of the most highlighted parts of the patient educational programs was breathing retraining. Since pursedlip breathing (PLB) is one of the most favored breathing techniques in patients with COPD [25], it remains unknown whether patients with IPF would also benefit from PLB. Although most studies that provided breathing retraining to IPF patients also used the PLB technique, the respiratory pathophysiologies of COPD and IPF are very different. Since patients with IPF do not suffer from obstructed airways, it is not likely that positive expiratory pressure breathing may be helpful primarily. Use of an intense PLB technique could increase the work of breathing in patients with restrictive lung diseases. The respiratory pathophysiology in IPF requires an increased breathing frequency, especially during physical activity. However, some patients tend to develop an unnecessary degree of hyperventilation. In order to regain breathing control, a slight PLB technique could be helpful to adjust the breathing frequency to an appropriate level even in IPF patients.

Generally, in IPF the emphasis in breathing retraining should be on teaching those techniques for breathing control and diaphragmatic effort to prevent tachypnea and anxiety and to improve gas exchange [26]. Since many IPF patients develop rigid rib cage structures, thoracic expansion exercises or stretching of the thoracic muscles may also be beneficial in patients with restrictive lung diseases.

\section{Exercise Capacity}

Only one of the studies [19] was performed as a randomized controlled trial investigating PR versus a control group in patients with IPF. Twenty-eight patients (FVC $=69 \%$ predicted) were randomly assigned either to a 10 -week outpatient PR program $(\mathrm{n}=13)$ mainly consisting of exercise training or to a control group. The control group $(n=15)$ did not receive any physical interven- tion. Measurements lung function, arterial blood gases, or dyspnea intensity revealed no significant effects of PR. Nevertheless, the 6-min walk distance (6MWD) improved significantly only in the PR group, whereas it remained unchanged in the control group (mean difference between groups in change from baseline $46.3 \mathrm{~m} ; \mathrm{p}<0.01$; 95\% CI 8.3-84.4 m).

All other studies except for one [20] included in this review also found significant short-term improvements in exercise capacity in patients with IPF following PR. Exercise capacity was mainly determined by the 6MWD. Only half of the studies $[18,19,21,23]$ achieved an increase in walk distance above the expected minimal important difference (MID) of about $28 \mathrm{~m}$ for IPF patients [27] (fig. 1). There were no obvious different variables with regard to the study populations (disease severity etc.) or to the different PR programs that might have explained these heterogeneous results.

In a small trial [20] $(\mathrm{n}=13 \mathrm{IPF}$ patients, $\mathrm{FVC}=67 \%$ predicted) no changes in $6 \mathrm{MWD}(383 \pm 115$ vs. $375 \pm$ $101 \mathrm{~m}$; n.s.) following a mostly unsupervised 8-week homebased PR program were observed. Nevertheless, a significant decrease in maximum heart rate during the $6 \mathrm{MWD}$ was reported ( $120 \pm 19$ vs. $101 \pm 12 \mathrm{bpm} ; \mathrm{p}<0.01)$. Surprisingly, patients showed an endurance time which was twice as high after PR $(7.4 \pm 9.1$ vs. $14.1 \pm 12.0 \mathrm{~min} ; \mathrm{p}<0.01)$ on a cycle ergometer while breathing room air. This might be due to the fact that this PR program was mainly focused on a cycling-based exercise program. However, the small sample size of this study has to be considered.

Kozu et al. [17] also evaluated changes in quadriceps strength in $36 \mathrm{IPF}$ patients (FVC $=69 \%$ predicted) following an 8-week outpatient PR program and reported an increase of $10 \%$ in the maximal isometric knee extension maneuver. This is substantially less than what can be expected in patients with COPD. On average, COPD patients have been shown to improve their quadriceps strength after PR by up to 25\% [28].

Also the disease severity of IPF may play a role in improving exercise capacity after $\mathrm{PR}$, although there are inconsistent findings. A Japanese study [18] enrolled 65 IPF patients $(\mathrm{FVC}=65 \%$ predicted) in an 8-week PR program. Subjects with Medical Research Council (MRC; grades 1-5) grades 2, 3, and 4 [29] underwent a supervised outpatient program, whereas subjects with MRC grade 5 participated in an unsupervised, home-based program including a visit from a home care provider every 2 weeks. In this study only patients with MRC grades 2 and 3 improved their 6MWD significantly. In contrast, patients with MRC grade 4 showed only small improve- 
Fig. 1. Changes in 6MWD in patients with IPF following PR. The dashed line represents the MID of $28 \mathrm{~m}$ in 6MWD in patients with IPF [27].

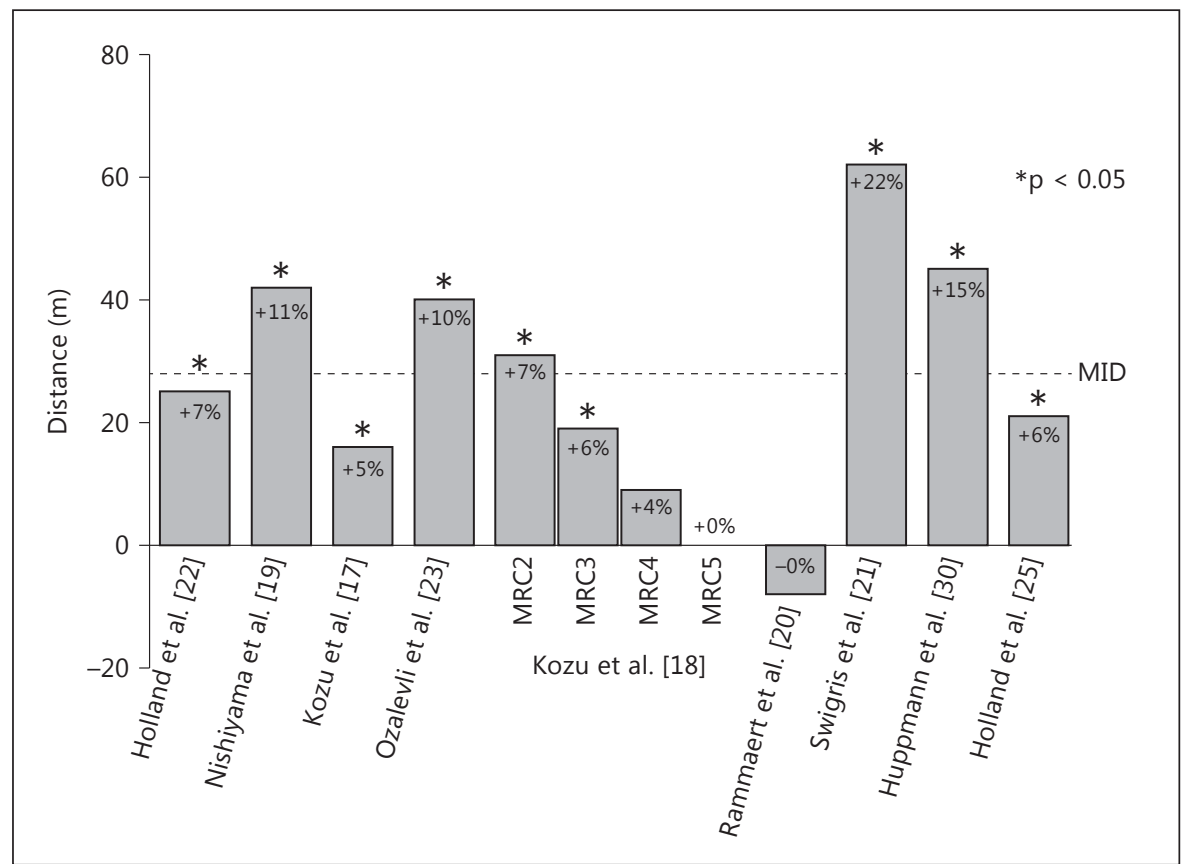

ments, and those with grade 5 showed no improvements. In contrast to these findings, a recently published study by Huppmann et al. [30] investigated a specialized, comprehensive, 4-week inpatient PR program in 402 German patients with ILD (including 202 IPF patients, mean $\mathrm{VC}=53 \%$ predicted). The improvement in $6 \mathrm{MWD}$ after PR was $45 \pm 55 \mathrm{~m}$ (range -130 to $236 \mathrm{~m}$ ), approximately $15 \%$ of the baseline value $(\mathrm{p}<0.001)$. Of all of the variables tested (age, gender, BMI, smoking history, use of LTOT, baseline FVC, baseline 6MWD, and baseline dyspnea), only the baseline 6MWD was a significant predictor of change in 6MWD. The mean improvement in 6MWD was higher in patients with a short baseline 6MWD (fig. 2). A subgroup analysis showed significant improvements in ILD patients independently of their underlying form of ILD (fig. 3).

What might be possible reasons for such contrasting results between the publications of Kozu et al. [18] and Huppmann et al. [30]? Firstly, in the study by Kozu et al. [18] the most disabled patients (MRC grade 5) with a mean vital capacity (VC) of $51 \%$ predicted underwent home-based and mostly unsupervised exercise training, which might not be the ideal approach for such severely impaired patients. Secondly, the MRC dyspnea scale may not be an appropriate tool to categorize and predict the changes in $6 \mathrm{MWD}$ in IPF patients. As the study by Huppmann et al. [30] investigated a very large and equal-

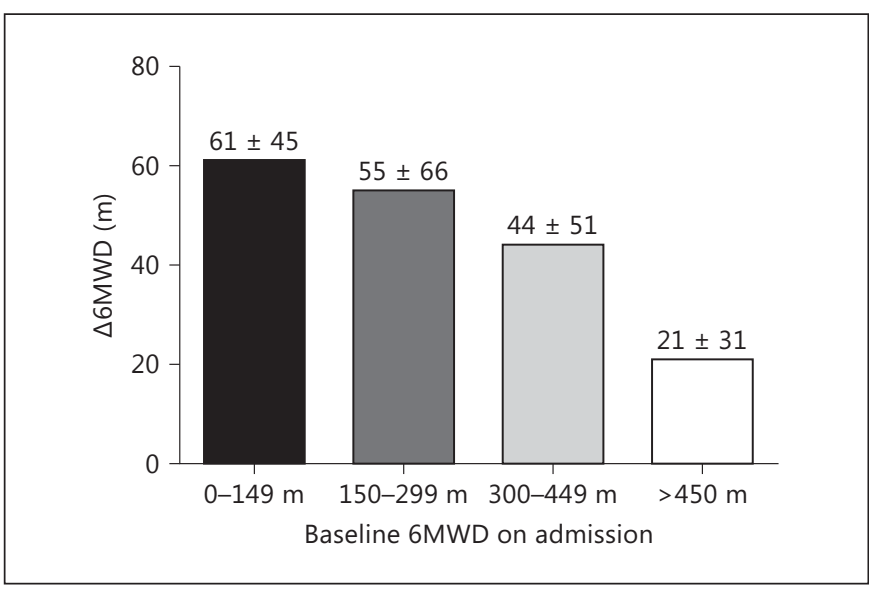

Fig. 2. The bars show the mean change in $6 \mathrm{MWD}$ during PR between admission and discharge depending on the baseline 6MWD in 202 patients with IPF. Data are provided by courtesy of Huppmann et al. [30].

ly disabled population ( $\mathrm{n}=202$ IPF patients, mean VC $53 \%$ predicted), the authors assumed that an intensive supervised PR might be more appropriate, especially in IPF patients with a severely impaired physical condition. This association was also confirmed by a retrospective study [31] that examined the effects of PR in 99 patients with ILD (mean FVC $=62 \%$ predicted, $n=50$ with IPF). These 


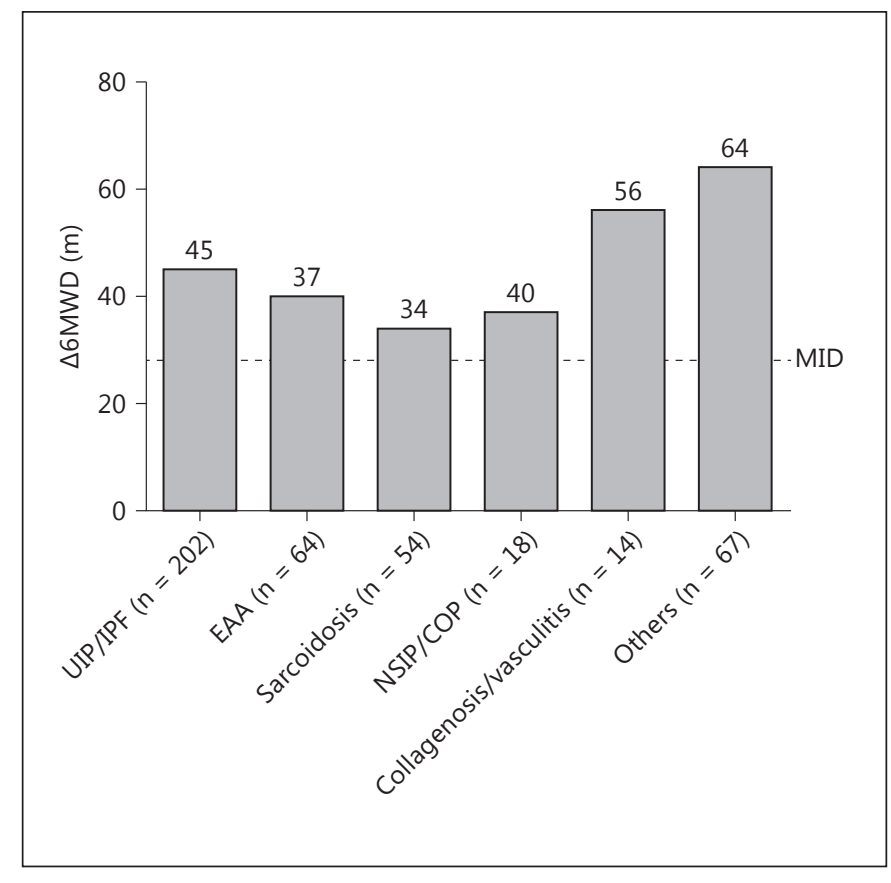

Fig. 3. The bars show the effects of PR on the 6MWD in different types of ILD. Data are provided courtesy of Huppmann et al. [30]. EAA = Exogen-allergic alveolitis; NSIP = nonspecific interstitial pneumonia; $\mathrm{COP}=$ cryptogenic organizing pneumonia.

authors also reported a negative correlation between lower baseline 6MWD and a greater increase following PR.

However, since exercise capacity has been recognized as a crucially important prognostic factor in IPF $[32,33]$, PR should mainly focus on improvement of the physical condition in those patients.

\section{Quality of Life}

Almost all of the studies in this review used different assessment measures to evaluate HRQL. Only two studies $[21,23]$ used the short-form 36-item (SF-36) questionnaire (scale 0-100), a disease-unspecific health survey tool. After a 12-week home-based PR program ( $\mathrm{n}=15$ IPF patients, FVC $=72 \%$ predicted), Ozalevli et al. [23] found significant improvements after PR in 3 out of 8 SF36 domains, i.e. general health ( 57 vs. 74 points, $\mathrm{p}<0.05$ ), physical role ( 25 vs. 68 points, $\mathrm{p}<0.01$ ), and emotional role ( 29 vs. 65 points, $\mathrm{p}<0.05$ ). Since the MID for the SF36 questionnaire in IPF is assumed at a range of 2-4 points [34], these improvements would represent a tremendous increase in these domains. However, from our perspective, this degree of improvement in SF-36 domains raises doubts. In contrast, Swigris et al. [21] found no significant improvement in any SF-36 domain after a 6-week outpatient $\mathrm{PR}$ program in $21 \mathrm{IPF}$ patients $(\mathrm{FVC}=$ $73 \%$ predicted), but they did find a possibly clinically relevant increase of $3.0 \pm 2.1$ in the physical component summary score. However, at least fatigue, a very bothersome symptom, was significantly reduced in this study (fatigue severity scale 4.2 vs. $2.7 ; \mathrm{p}=0.01$ ).

Nishiyama et al. [18] used the Saint George respiratory questionnaire (SGRQ) to evaluate HRQL during a 10week outpatient PR in $30 \mathrm{IPF}$ patients $(\mathrm{FVC}=69 \%$ predicted). Only the change in total SGRQ score reached a significant difference in favor of the PR group versus the control group not receiving PR (6.1 points, betweengroup difference, $\mathrm{p}<0.05)$. In patients with IPF, an improvement in SGRQ score of 5-8 points is estimated to be the MID [34].

Although several studies reported inconsistent results on HRQL, there is a strong indication that PR reveals HRQL benefits to a clinically relevant extent in IPF patients.

\section{Dyspnea}

To evaluate dyspnea as one of the most relevant disease-specific symptoms, the dyspnea domain of the chronic respiratory questionnaire (CRQ) with an assumed MID threshold of 2.5 points [35] was used in the study by Holland et al. [22]. After an 8-week outpatient PR program ( $\mathrm{n}=25, \mathrm{FVC}=76 \%$ predicted $)$, an improvement of $2.7 \pm 5.6$ points $(p>0.05)$ could be reached in the CRQ dyspnea domain. At program completion, 59\% of the IPF patients had achieved improvements in dyspnea exceeding the MID. This is less than the rate detected in a population of 19 patients with non-IPF ILDs (67\%) in this trial.

Two other studies $[17,18]$ investigated the effect of PR on dyspnea using Mahler's transition dyspnea index (TDI) [36]. This interviewer-administered questionnaire provides a multidimensional measurement of dyspnea that evokes dyspnea in ADL. With an overall increase of $0.8 \pm 1.7$ points after an 8 -week outpatient $P R$, these studies failed to show a significant or clinically relevant improvement in dyspnea, except for IPF patients categorized as MRC grade 2. These patients were able to improve their TDI by 1.6 points (95\% CI $1.0-2.3$ ), which is closely above the discussed MID of 1.5 points in patients with ILD [37]. Rammaert et al. [20] assessed breathless- 
ness using a visual analog scale ( $0-10$ points) and found a significant reduction $(5.8 \pm 1.8$ vs. $5.1 \pm 2.4 ; \mathrm{p}<0.025)$ in dyspnea in IPF patients following an 8-week homebased PR.

\section{PR in IPF versus Non-IPF Patients}

The above mentioned recently published study [30] evaluated 402 patients with ILD (including 202 IPF patients, mean $\mathrm{VC}=53 \%$ predicted) following a 4-week inpatient PR program. The authors found significant and clinically relevant improvements in functional exercise capacity (increase in 6MWD $46 \pm 3 \mathrm{~m}$ ) as well as HRQL (SF-36 physical component score $+6 \pm 1$ points; SF-36 mental component score $+10 \pm 1$ points; both $\mathrm{p}<0.001$ ). These benefits were independent of the underlying disease (IPF, cryptogenic organizing pneumonia, hypersensitivity pneumonitis, sarcoidosis, and others) (fig. 3). Patients with signs of pulmonary hypertension $(\mathrm{PH})$ showed a decreased baseline 6MWD $(277 \pm 12$ vs. $322 \pm 8 \mathrm{~m})$ and improved their 6MWD significantly less than did patients without $\mathrm{PH}$ ( $36 \pm 6$ vs. $48 \pm 3 \mathrm{~m}, \mathrm{p}=0.045$ ). However, the increase in $6 \mathrm{MWD}$ in ILD patients with $\mathrm{PH}$ was still significant and clinically meaningful [27].

In contrast, Holland et al. [22] found greater and more sustained benefits from PR when IPF severity was still mild, whereas those with other types of ILD achieved benefits regardless of disease severity. In IPF, greater improvements in 6MWD following $\mathrm{PR}$ were associated with a higher FVC $(\mathrm{r}=0.49, \mathrm{p}=0.01)$, less exercise-induced hypoxemia $\left(\mathrm{r}_{\mathrm{s}}=0.43, \mathrm{p}=0.04\right)$, and lower right ventricular systolic pressure $(\mathrm{r}=-0.47, \mathrm{p}=0.1)$. Moreover, patients with IPF also tended to improve their functional exercise capacity less than those with other types of ILDs (6MWD $21 \pm 58$ vs. $43 \pm 56 \mathrm{~m}, \mathrm{p}=0.21$ ). Improvements in $6 \mathrm{MWD}$ that exceeded the MID occurred in $40 \%$ of patients with IPF compared to $52 \%$ of those with other forms of ILD ( $p=0.41)$. A comparable cluster could be found concerning improvements in patients' dyspnea rating. The CRQ dyspnea domain improved slightly less in IPF patients compared to other types of ILD $(2.7 \pm 5.6$ vs. $4.6 \pm 5.2$ points, $\mathrm{p}=0.25$ ).

Since ILD is a heterogeneous group of disease, these authors hypothesized that patients with IPF would generally demonstrate greater abnormalities of exercise-induced hypoxemia $[38,39]$ and tend to improve less following PR [22]. The latter would not be in accordance with the findings of Huppmann et al. [30].
Moreover, when comparing the effects of an identical PR program for patients with COPD or IPF, COPD patients showed greater improvements in all outcome parameters compared to IPF patients (6MWD 53 vs. $16 \mathrm{~m}$, quadriceps force $5.4 \mathrm{vs} .2 .0 \mathrm{~kg}$, TDI score 1.8 vs. 0.8 points; all between-group differences with $p<0.05$ ) [17]. So far the underlying reasons for the different responses to $\mathrm{PR}$ between the two diseases remain unclear.

\section{Maintenance of PR Benefits in IPF}

In patients with COPD it is known that the benefits of PR can be maintained for up to 12-18 months [6]. To date there is no reliable evidence of long-term effects of $\mathrm{PR}$ in patients with IPF. In a single small study [40] including 34 patients ( $\mathrm{FVC}=76 \%$ predicted), no effects of physical training on exercise capacity, HRQL, or survival could be preserved over a period of 6 months after PR. Only a small subgroup with severe disease still had significantly improved HRQL compared to controls at that time. It also seems to be much more unlikely for patients with IPF to preserve benefits of PR compared to other forms of ILD. Six months after PR, only $35 \%$ of patients with IPF had maintained gains in 6MWD that exceeded the MID, compared to $41 \%$ of patients with other types of ILD. Also, improvements in dyspnea above the MID were observed in non-IPF patients more often compared to IPF patients (56 vs. $24 \%$; $\mathrm{p}<0.05$ ) at 6 months after PR. However, in another small study Naji et al. [41] ( $\mathrm{n}=15$ ILD patients, no notification on IPF) reported improvements in exercise capacity that were still maintained 1 year after PR. The authors even found a sustained and significant reduction in hospital admission days noted 1 year after the intervention.

In a Japanese study [17], the limitations of ADL were assessed using a standard scoring system [42]. This ADL score evaluates 6 basic daily activities (feeding, transfer, dressing, bathing, shopping, and transportation). The ADL score improved significantly after an 8-week PR program and this was the only outcome parameter that could be preserved over a 6-month follow-up period (3.7 \pm 1.2 vs. $4.8 \pm 1.1$ vs. $4.3 \pm 1.2$; all $\mathrm{p}<0.01)$. At follow-up all other parameters $(6 \mathrm{MWD}$, quadriceps force, SF-36, MRC grade) declined to baseline values before PR. The finding that the ADL score was preserved at follow-up was explained by the patient education component that aimed to improve the ability of subjects to perform ADLs.

The duration of the PR program may also play a certain role. One study [43] investigated 10 patients with
Kenn/Gloeckl/Behr 
ILDs (FVC $=47 \%$ predicted $)$ and observed highly relevant benefits in clinical outcome parameters after 12 weeks of PR, with an even greater gain when the program was extended to 24 weeks (6MWD baseline $321 \pm 155 \mathrm{~m}$ vs. $400 \pm 184 \mathrm{~m}$ vs. $428 \pm 211 \mathrm{~m}$; each p < 0.05). Nevertheless, for many health care systems it might be difficult to establish such long-lasting PR programs. Indeed, a conceivable solution could be to instruct and motivate patients to maintain home-based follow-up training modalities in order to sustain PR benefits [44].

\section{Unmet Needs for an IPF-Specific PR Approach}

The question of which aims should be addressed and which components ideally should be included in an IPFspecific PR program remains unanswered. It is not yet known which modifications of PR programs for IPF patients may be useful or necessary in comparison to PR programs for patients with COPD. However, one study [17] could show that a PR program based on guidelines for subjects with COPD had a lower efficacy when applied to individuals with advanced IPF. These results suggest either that a disease-specific modification of PR programs might be necessary in IPF or that the response to the various components of PR may be more limited due to the different underlying pathophysiologies of ILDs, especially IPF.

Nevertheless, with regard to the above described studies, it seems to be likely that individually tailored exercise training (a combination of aerobic endurance and strength training) may also be an important component in PR in patients with IPF. Exercise training was the only modality applied in all studies that investigated PR in IPF. To date, it is unclear whether IPF patients would require different training strategies than COPD patients. Especially for more severely disabled IPF patients, endurance training may be more feasible when applied as an interval training mode with short bouts of high-intensity cycling alternating with longer periods of rest as shown in advanced COPD [45]. One can speculate that this might be even more important since IPF patients seem to perceive higher degrees of dyspnea on exertion [46] and thus a more pronounced limitation in endurance capacity compared to patients with COPD. Furthermore, disease-specific education including coping skills and self-management plans for situations of severe dyspnea in order to prevent or to reduce panic attacks, stress, anxiety, and/or depression could be a useful component in an IPF-specific PR program. Additionally, disease-specific breathing retraining sessions (e.g. respiratory control or reducing tachypnea) as well as teaching energy conservation strategies may also be helpful adjuncts for the patients' daily life. As we have learned from COPD patients, the issue of psychiatric comorbidities such as anxiety, panic, and/or depression [47] as well as end-of-life communication [48] represents a relevant part of the burden even in early phases of the disease. It is most likely that in IPF patients these issues should be considered and addressed in the general disease management. PR may be an appropriate 'window of opportunity' to deal with these problems. Studies in this area are lacking.

The role of oxygen supplementation (LTOT) in patients with hypoxemia during exertion and/or at rest (not addressed in the discussed trials but probably of high clinical relevance) has to be discussed and evaluated in the future. Currently the IPF-specific guidelines include a strong recommendation, albeit with very low-quality evidence, for the use of LTOT [1]. In our opinion, sufficient compensation in oxygen deficiencies may be an important key for increasing the ability of IPF patients to perform and to sustain any kind of physical activity. However, potential negative effects of oxygen, although never reported in IPF patients, have to be considered and ruled out. Consequently there is definitely an unmet need for further studies in this area.

New training modalities besides conventional exercise methods, such as neuromuscular electrical muscle stimulation [49, 50], inspiratory muscle training [51, 52], whole-body vibration training [53], or noninvasive ventilation [54,55], have been shown to be beneficial in patients with advanced COPD. It could be hypothesized that these therapeutic interventions may also be useful in IPF. The same may be true for alternative exercise and relaxation techniques like tai chi or yoga which have recently been shown to improve HRQL and even lung function [56-58] in COPD. Still, there remain many unanswered questions for an IPF-specific PR program: what is the optimal duration and intensity for PR? What is the ideal timing for PR in disease progression? What strategies can be established to preserve PR benefits over time?

\section{Conclusion}

Although positive short-term effects of $\mathrm{PR}$ in patients with IPF have been reported in several studies, its role in the context of an available therapeutic option has yet to be established. Future studies have to evaluate if there is a need for a standardized IPF-specific PR program also 
addressing psychiatric comorbidities and including endof-life communication. Moreover the optimal timing and duration of $\mathrm{PR}$ have to be detected. According to the still low level of evidence for PR, only a minority of patients with IPF have been referred to PR. Currently, many physicians as well as patients themselves still believe that exercise training may not be feasible or may even be harmful [59]. Data from this review show clinically important effects (at least on a short-term basis) for patients across the spectrum of different types of ILD. Thus PR may evolve into a meaningful additional option in the treatment of patients with IPF in the future. As has been demonstrated in COPD, the inclusion of exercise training performed most likely as a combination of endurance and resistance training seems to be the most important component and might become highly recommendable. Additionally, a disease-specific educational program as well as special breathing retraining sessions may also be useful adjuncts to augment patients' disease management.

Based on our current knowledge, admission criteria for PR programs should also include the group of IPF patients and facilitate their early and repetitive participation. Future research is needed and should focus on the proof of concept that PR is effective in IPF patients and that the benefits can be preserved over time, thus positively impacting the clinical course of the disease. In the long run it must be evaluated whether there is a need for IPF-specific PR programs as an important part of this nonpharmaceutical therapeutic approach.

\section{References}

1 Raghu G, Collard HR, Egan JJ, Martinez FJ, Behr J, Brown KK, et al: An official ATS/ERS/ JRS/ALAT statement: idiopathic pulmonary fibrosis - evidence-based guidelines for diagnosis and management. Am J Respir Crit Care Med 2011;183:788-824.

-2 Poletti V, Ravaglia C, Buccioli M, Tantalocco P, Piciucchi S, Dubini A, Carloni A, Chilosi M, Tomassetti S: Idiopathic pulmonary fibrosis: diagnosis and prognostic evaluation. Respiration 2013;86:5-12.

3 Cottin V, Camus P: Practical issues and challenges in idiopathic pulmonary fibrosis. Respiration 2013;86:1-4.

4 Selman M, Thannickal VJ, Pardo A, Zisman DA, Martinez FJ, Lynch JP 3rd: Idiopathic pulmonary fibrosis: pathogenesis and therapeutic approaches. Drugs 2004;64:405-430.

5 Lacasse Y, Martin S, Lasserson TJ, Goldstein RS: Meta-analysis of respiratory rehabilitation in chronic obstructive pulmonary disease: a Cochrane systematic review. Eura Medicophys 2007;43:475-485.

-6 Nici L, ZuWallack R, Wouters E, Donner CF: The ATS/ERS statement on pulmonary rehabilitation. Eur Respir J 2006;28:461-462.

7 Harrison SL, Greening NJ, Williams JE, Morgan MD, Steiner MC, Singh SJ: Have we underestimated the efficacy of pulmonary rehabilitation in improving mood? Respir Med 2012;106:838-844.

8 Katzenstein AL, Myers JL: Idiopathic pulmonary fibrosis: clinical relevance of pathologic classification. Am J Respir Crit Care Med 1998;157:1301-1315.

9 GOLD: Global strategy of the diagnosis, management, and prevention of chronic obstructive pulmonary disease. 2013. http://www. goldcopd.org (accessed May 3, 2013).

10 Ryerson CJ, Arean PA, Berkeley J, CarrieriKohlman VL, Pantilat SZ, Landefeld CS, et al:
Depression is a common and chronic comorbidity in patients with interstitial lung disease. Respirology 2012;17:525-532.

11 Widimsky J, Riedel M, Stanek V: Central haemodynamics during exercise in patients with restrictive pulmonary disease. Bull Eur Physiopathol Respir 1977;13:369-379.

12 Chang JA, Curtis JR, Patrick DL, Raghu G: Assessment of health-related quality of life in patients with interstitial lung disease. Chest 1999;116:1175-1182.

13 Swigris JJ, Kuschner WG, Jacobs SS, Wilson SR, Gould MK: Health-related quality of life in patients with idiopathic pulmonary fibrosis: a systematic review. Thorax 2005;60:588594.

14 Rafii R, Juarez MM, Albertson TE, Chan AL: A review of current and novel therapies for idiopathic pulmonary fibrosis. J Thorac Dis 2013;5:48-73.

15 Dowman L, McDonald CF, Hill C, Lee A, Barker K, Boote C, et al: The benefits of exercise training in interstitial lung disease: protocol for a multicentre randomised controlled trial. BMC Pulm Med 2013;13:8.

16 Puhan MA, Schunemann HJ, Frey M, Scharplatz M, Bachmann LM: How should COPD patients exercise during respiratory rehabilitation? Comparison of exercise modalities and intensities to treat skeletal muscle dysfunction. Thorax 2005;60:367-375.

17 Kozu R, Senjyu H, Jenkins SC, Mukae H, Sakamoto N, Kohno S: Differences in response to pulmonary rehabilitation in idiopathic pulmonary fibrosis and chronic obstructive pulmonary disease. Respiration 2011;81:196-205.

18 Kozu R, Jenkins S, Senjyu H: Effect of disability level on response to pulmonary rehabilitation in patients with idiopathic pulmonary fibrosis. Respirology 2011;16:1196-1202.
19 Nishiyama O, Kondoh Y, Kimura T, Kato K, Kataoka K, Ogawa T, et al: Effects of pulmonary rehabilitation in patients with idiopathic pulmonary fibrosis. Respirology 2008; 13:394-399.

20 Rammaert B, Leroy S, Cavestri B, Wallaert B, Grosbois JM: Home-based pulmonary rehabilitation in idiopathic pulmonary fibrosis. Rev Mal Respir 2011;28:e52-e57.

21 Swigris JJ, Fairclough DL, Morrison M, Make B, Kozora E, Brown KK, et al: Benefits of pulmonary rehabilitation in idiopathic pulmonary fibrosis. Respir Care 2011;56:783-789.

22 Holland AE, Hill CJ, Glaspole I, Goh N, McDonald CF: Predictors of benefit following pulmonary rehabilitation for interstitial lung disease. Respir Med 2012;106:429-435.

23 Ozalevli S, Karaali HK, Ilgin D, Ucan ES: Effect of home-based pulmonary rehabilitation in patients with idiopathic pulmonary fibrosis. Multidiscip Respir Med 2010;5:31-37.

24 Holland A, Hill C: Physical training for interstitial lung disease. Cochrane Database Syst Rev 2008, p CD006322.

25 Holland AE, Hill CJ, Jones AY, McDonald CF: Breathing exercises for chronic obstructive pulmonary disease. Cochrane Database Syst Rev 2012;10:CD008250.

26 Swigris JJ, Brown KK, Make BJ, Wamboldt FS: Pulmonary rehabilitation in idiopathic pulmonary fibrosis: a call for continued investigation. Respir Med 2008;102:1675-1680.

27 Swigris JJ, Wamboldt FS, Behr J, du Bois RM, King TE, Raghu G, et al: The 6 minute walk in idiopathic pulmonary fibrosis: longitudinal changes and minimum important difference. Thorax 2010;65:173-177.

28 O'Shea SD, Taylor NF, Paratz JD: Progressive resistance exercise improves muscle strength and may improve elements of performance of daily activities for people with COPD: a systematic review. Chest 2009;136:1269-1283. 
-29 Fletcher CM, Elmes PC, Fairbairn AS, Wood $\mathrm{CH}$ : The significance of respiratory symptoms and the diagnosis of chronic bronchitis in a working population. Br Med J 1959;2: 257-266.

-30 Huppmann P, Sczepanski B, Boensch M, Winterkamp S, Schönheit-Kenn U, Neurohr C, Behr J, Kenn K: Effects of in-patient pulmonary rehabilitation in patients with interstitial lung disease. Eur Respir J 2012;42:444-445.

- 31 Ferreira A, Garvey C, Connors GL, Hilling L, Rigler J, Farrell S, et al: Pulmonary rehabilitation in interstitial lung disease: benefits and predictors of response. Chest 2009;135:442447.

-32 Lederer DJ, Arcasoy SM, Wilt JS, D’Ovidio F, Sonett JR, Kawut SM: Six-minute-walk distance predicts waiting list survival in idiopathic pulmonary fibrosis. Am J Respir Crit Care Med 2006;174:659-664.

-33 Swigris JJ, Swick J, Wamboldt FS, Sprunger D, du Bois R, Fischer A, et al: Heart rate recovery after 6-min walk test predicts survival in patients with idiopathic pulmonary fibrosis. Chest 2009; 136:841-848.

- 34 Swigris JJ, Brown KK, Behr J, du Bois RM, King TE, Raghu G, et al: The SF-36 and SGRQ: validity and first look at minimum important differences in IPF. Respir Med 2010; 104:296-304.

- 35 Jaeschke R, Singer J, Guyatt GH: Measurement of health status: ascertaining the minimal clinically important difference. Control Clin Trials 1989;10:407-415.

- 36 Mahler DA, Weinberg DH, Wells CK, Feinstein AR: The measurement of dyspnea: contents, interobserver agreement, and physiologic correlates of two new clinical indexes. Chest 1984;85:751-758.

37 Khanna D, Tseng CH, Furst DE, Clements PJ, Elashoff R, Roth M, et al: Minimally important differences in the Mahler's transition dyspnoea index in a large randomized controlled trial - results from the Scleroderma Lung Study. Rheumatology (Oxford) 2009; 48:1537-1540.

38 Agusti AG, Roca J, Rodriguez-Roisin R, Xaubet A, Agusti-Vidal A: Different patterns of gas exchange response to exercise in asbestosis and idiopathic pulmonary fibrosis. Eur Respir J 1988;1:510-516.
39 Wells AU, Hansell DM, Rubens MB, Cailes JB, Black CM, du Bois RM: Functional impairment in lone cryptogenic fibrosing alveolitis and fibrosing alveolitis associated with systemic sclerosis: a comparison. Am J Respir Crit Care Med 1997;155:1657-1664.

40 Holland AE, Hill CJ, Conron M, Munro P, McDonald CF: Short term improvement in exercise capacity and symptoms following exercise training in interstitial lung disease. Thorax 2008;63:549-554.

41 Naji NA, Connor MC, Donnelly SC, McDonnell TJ: Effectiveness of pulmonary rehabilitation in restrictive lung disease. J Cardiopulm Rehabil 2006;26:237-243.

42 Spector WD, Katz S, Murphy JB, Fulton JP: The hierarchical relationship between activities of daily living and instrumental activities of daily living. J Chronic Dis 1987;40:481-489.

-43 Salhi B, Troosters T, Behaegel M, Joos G, Derom E: Effects of pulmonary rehabilitation in patients with restrictive lung diseases. Chest 2010;137:273-279.

-44 Jastrzebski D, Gumola A, Gawlik R, Kozielski $\mathrm{J}$ : Dyspnea and quality of life in patients with pulmonary fibrosis after six weeks of respiratory rehabilitation. J Physiol Pharmacol 2006; 57(suppl 4):139-148.

45 Gloeckl R, Halle M, Kenn K: Interval versus continuous training in lung transplant candidates: a randomized trial. J Heart Lung Transplant 2012;31:934-941.

46 Gloeckl R, Halle M, Kenn K: Differences in feasibility of interval training between patients with end-stage COPD and interstitial lung disease before lung transplantation - a pilot study. Am J Respir Crit Care Med 2012; 185:A2390.

47 Gudmundsson G, Gislason T, Janson C, Lindberg E, Suppli Ulrik C, Brondum E, et al: Depression, anxiety and health status after hospitalisation for COPD: a multicentre study in the Nordic countries. Respir Med 2006;100: 87-93.

48 Stenzel N, Rief W, Kuhl K, Pinzer S, Kenn K: Fear of progression and end-of-life fear in COPD patients (in German). Pneumologie 2012;66:111-118

49 Sillen MJ, Speksnijder CM, Eterman RM, Janssen PP, Wagers SS, Wouters EF, et al: Effects of neuromuscular electrical stimulation of muscles of ambulation in patients with chronic heart failure or COPD: a systematic review of the English-language literature. Chest 2009;136:44-61.
50 Vivodtzev I, Debigare R, Gagnon P, Mainguy V, Saey D, Dube A, et al: Functional and muscular effects of neuromuscular electrical stimulation in patients with severe COPD: a randomized clinical trial. Chest 2012;141:716725 .

51 Gosselink R, De Vos J, van den Heuvel SP, Segers J, Decramer M, Kwakkel G: Impact of inspiratory muscle training in patients with COPD: what is the evidence? Eur Respir J 2011;37:416-425.

52 Geddes EL, Reid WD, Crowe J, O'Brien K, Brooks D: Inspiratory muscle training in adults with chronic obstructive pulmonary disease: a systematic review. Respir Med 2005; 99:1440-1458.

53 Gloeckl R, Heinzelmann I, Baeuerle S, Damm E, Schwedhelm AL, Diril M, et al: Effects of whole body vibration in patients with chronic obstructive pulmonary disease - a randomized controlled trial. Respir Med 2012;106: 75-83.

54 Kohnlein T, Schonheit-Kenn U, Winterkamp S, Welte T, Kenn K: Noninvasive ventilation in pulmonary rehabilitation of COPD patients. Respir Med 2009;103:1329-1336.

55 Duiverman ML, Wempe JB, Bladder G, Jansen DF, Kerstjens HA, Zijlstra JG, et al: Nocturnal non-invasive ventilation in addition to rehabilitation in hypercapnic patients with COPD. Thorax 2008;63:1052-1057.

56 Yan JH, Guo YZ, Yao HM, Pan L: Effects of tai chi in patients with chronic obstructive pulmonary disease: preliminary evidence. PLoS One 2013;8:e61806.

57 Soni R, Munish K, Singh K, Singh S: Study of the effect of yoga training on diffusion capacity in chronic obstructive pulmonary disease patients: a controlled trial. Int J Yoga 2012;5: 123-127.

58 Leung RW, McKeough ZJ, Peters MJ, Alison JA: Short-form Sun-style t'ai chi as an exercise training modality in people with COPD. Eur Respir J 2013;41:1051-1057.

59 Collard HR, Loyd JE, King TE Jr, Lancaster $\mathrm{LH}$ : Current diagnosis and management of idiopathic pulmonary fibrosis: a survey of academic physicians. Respir Med 2007;101: 2011-2016.

60 Gloeckl R, Marinov B, Pitta F: Practical recommendations for exercise training in patients with COPD. Eur Respir Rev 2013; 22:178-186. 